\title{
Evaluation of equipment used in Ex atmospheres - interdisciplinary field
}

\author{
Sorin Burian, Danut Grecea*, and Gabriela Pupazan \\ National Institute for Research and Development in Mine Safety and Protection to Explosion - \\ INSEMEX, 32-34 G-ral Vasile Milea Street, Petrosani, Romania
}

\begin{abstract}
The risk of explosion becomes significant when, in the industrial field, flammable substances such as gases, vapours, mists, dusts, lint and fibres may be present. If they are present in sufficient quantity, the risk of explosion is imminent. On the other hand, the measure of shutting down the technical equipment, in the context of the presence of explosive atmospheres, is not an acceptable measure in all situations. As examples are the parts of installations that have safety functions: ventilation installations, installations for monitoring the concentration of flammable substances and other safety parameters. Explosion protection of technical equipment shall be evaluated and tested in order to validate it. The testing process of the technical equipment for the purpose of explosion protection certification is situated at the confluence of several engineering fields: mechanical, electrical, chemical, etc. The first part of the paper deals with the risk of explosion and presents the explosion protection of the technical equipment. The systematized presentation of the technical equipment tests is performed in the second part of the paper. Among the conclusions it is mentioned that although the field of tests in explosion atmospheres is an interdisciplinary one, its coherence is ensured by the specific standards.
\end{abstract}

\section{Introduction}

In the industrial field in general, and production of energy based on fossil fuels, transport, extraction, processing, storage of petroleum products in particular, the interaction with various substances is predominant, most of which are combustible and explosive. The use of technical equipment in activities related to storage, transfer and / or processing of this type of substance involves formation, in their vicinity, of a specific area with a significant risk of explosion. [1]

The use of technical equipment in these areas where there is a possibility of formation of explosive atmospheres is clearly regulated, so to meet these requirements, methods and preventive solutions have been proposed to minimize the risk of unwanted events.

Explosion prevention and protection are of major importance for health and safety at work. For an atmosphere to become explosive, the flammable substance must be present in certain concentrations. Therefore, the explosion can only occur if there is a source of ignition and only if the concentration falls within the flammability (explosivity) limits of

${ }^{*}$ Corresponding author : danut.grecea@insemex.ro 
the substance, i.e., between lower flammability limit and upper flammability limit. The flammability (explosivity) limits of substance depend on pressure and oxygen concentration in the air. Thus, the mechanism of an explosion generated by a mixture of flammable gases, vapours or vapours with air can be expressed by the well-known explosion triangle, shown in Figure 1 (a) and explosion pentagon for or dusts, lint and fibres, Figure 1 (b). From this representation it can be concluded that an explosion can occur if three conditions are met simultaneously [2-4]:

1. presence of fuel (flammable gases, vapours, dust, mists, fibres);

2. presence of oxygen, oxidizing substances;

3. efficient ignition source.

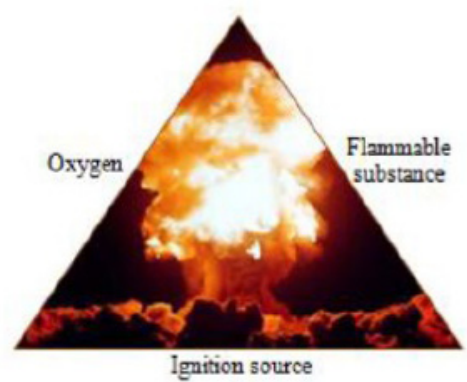

a)

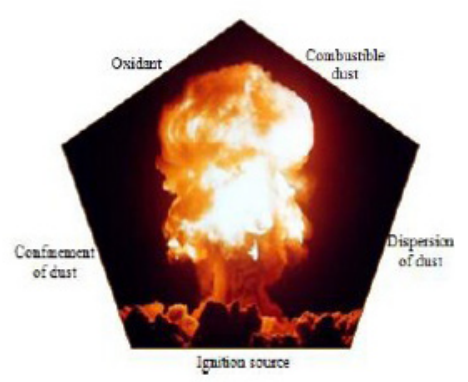

b)

Fig. 1. a) explosion triangle (for gases, vapours, mists); b) explosion pentagon (for dusts, lint and fibres).

The dust explosion has different characteristics from the gas explosion and can be in many cases more devastating. If, for example, a stream of air swirls a layer of dust, in a small space, dust along the oxygen generates a flammable mixture of air-dust. If this mixture is ignited by a source of ignition, it will explode. The force of explosion swirls more dust in the air, being ignited in turn, like a chair reaction. [3]

New concepts for explosion prevention and protection develop new strategies to prevent the propagation of explosions or to limit their effects, by taking into account specific related to the explosive mixture (limitation, containment, etc.).

Consideration must also be given to the fact that in order to be considered a combustible dust, the dust must be explosive - it must be suspended in the air, in order to have a distribution of particles capable of propagating combustion and a concentration, between explosion limits. Therefore, the explosion pentagon shown in Figure 1 (b) can be defined by adding to explosion triangle aspects related to mixture or dispersion of conbustible substances and oxidant, as well as those related to mixture suspensions.

This representation provides a clear picture of the explosion conditions and allows identification of safety measures for design, manufacture, installation and repair of installations in order to prevent an explosive atmosphere, to eliminate sources of ignition or to reduce the effects of explosions by using protective systems.

\section{Types of explosion protection}

All equipment used in installations operating in potentially explosive atmospheres must meet the following requirements [4]:

- be adequately protected to explosion;

- maintain degree of protection to environmental conditions for which they were built; 
- be able to withstand all the stresses to which they are subjected during storage, transport, installation and operation of installation.

All constructive solutions applied to electrical or non-electrical equipment that are used in potentially explosive atmospheres, in order to avoid the ignition of the surrounding explosive atmosphere, are included in specific represent types of protection. Constructively, electrical equipment may be designed using two or mor types of protection, specified by manufacturer on the label, in accordance with the requirements of applicable standards. Each type of protection is based on a specific technical solution in order to implement explosion protection, Table 1. [4-9]

Table 1. Technical solutions and types of protection.

\begin{tabular}{|c|c|c|}
\hline \multicolumn{2}{|c|}{ Types of protection to explosion } & \multirow{2}{*}{ Technical solution used } \\
\hline Symbol & Name & \\
\hline Ex m & Encapsulation „m” & \multirow{3}{*}{$\begin{array}{l}\text { Separates electrical equipment or parts that are } \\
\text { likely to cause explosive atmospheric ignition }\end{array}$} \\
\hline Ex $p$ & Pressurized enclosure „,p” & \\
\hline Ex q & Powder filling „," & \\
\hline Ex e & Increased safety ,e” & \multirow{2}{*}{ Eliminates the ignition source } \\
\hline Ex n & Type of protection „n” & \\
\hline Ex d & Flameproof enclosures „,d” & $\begin{array}{l}\text { Prevents the ignition from spreading } \\
\text { throughout the mixture in hazardous area }\end{array}$ \\
\hline Ex i & Intrinsic safety ,i” & $\begin{array}{l}\text { It limits electric energy in circuits that can be a } \\
\text { source of ignition }\end{array}$ \\
\hline
\end{tabular}

The correlation of the types of protection with EPL (Equipment Protection Level), [10], and the area in which they can be used is presented in Figure 2.

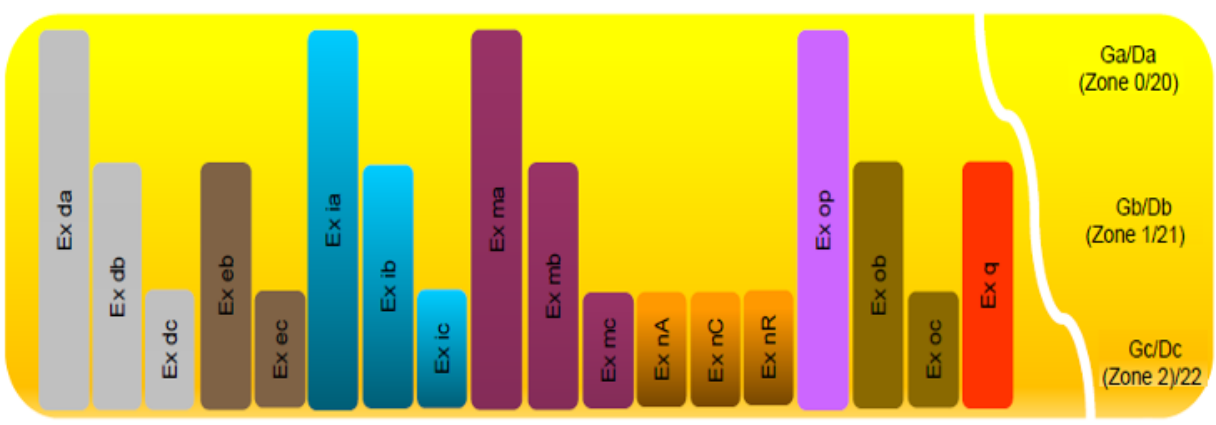

Fig. 2. Correlation between the types of protection and the equipment EPL/ corresponding area.

\section{Electrical equipment evaluation and testing for certification}

The certification process of equipment used in potentially explosive environments involves also testing, in addition to evaluation of equipment, to demonstrate practical compliance with the requirements set by specific standards [11]. 
From a constructive point of view, the equipment must use materials that are not affected by the environmental conditions in which they are installed and especially not to bring an additional risk in minimizing explosion risk. Table 2 presents the construction requirements (metallic materials, non-metallic materials, elastomeric materials and plastics), in correlation with EPL, according to SR EN 60079-0 [4], [12].

Table 2. Synthesis of specific requirements for material type in corelation with EPL.

\begin{tabular}{|c|c|c|c|c|}
\hline $\begin{array}{c}\text { EPL/ } \\
\text { Material }\end{array}$ & Metallic & Non-Metallic & Elastomeric & Plastics \\
\hline Ga & $\begin{array}{c}\leq 10 \% \text { in total of } \\
\text { aluminium, magnesium, } \\
\text { titanium and zirconium } \\
\text { and } \\
\leq 7.5 \% \text { in total of } \\
\text { magnesium, titanium } \\
\text { and zirconium }\end{array}$ & \multirow{4}{*}{ 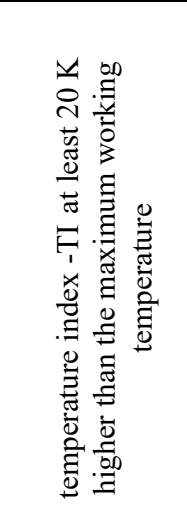 } & \multirow{4}{*}{ 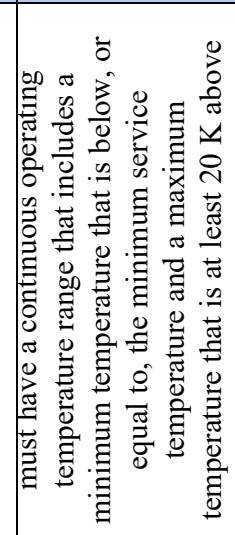 } & \multirow{4}{*}{ 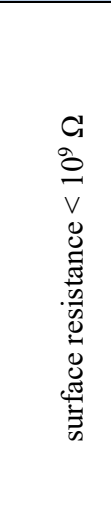 } \\
\hline Da & $\begin{array}{l}\leq 7.5 \% \text { in total of } \\
\text { magnesium, titanium } \\
\text { and zirconium }\end{array}$ & & & \\
\hline Gb and Db & $\begin{array}{l}\leq 7.5 \% \text { in total of } \\
\text { magnesium, titanium } \\
\text { and zirconium }\end{array}$ & & & \\
\hline Gc and Dc & no requirements & & & \\
\hline
\end{tabular}

In case of electrical equipment designed for use in explosive atmospheres, depending on the type of protection, are applicable general type tests according-SR EN 60079-0, as well as type tests specific for each type of protection (for flameproof enclosures , d"according SR EN 60079-1, pressurized enclosure „p"-according SR EN 60079-2, increased safety ,e"-according SR EN 60079-7, intrinsic safety ,i”-according SR EN 60079-11 and encapsulation ,m”-according SR EN 60079-18) synthetically in Figure 3- 5.
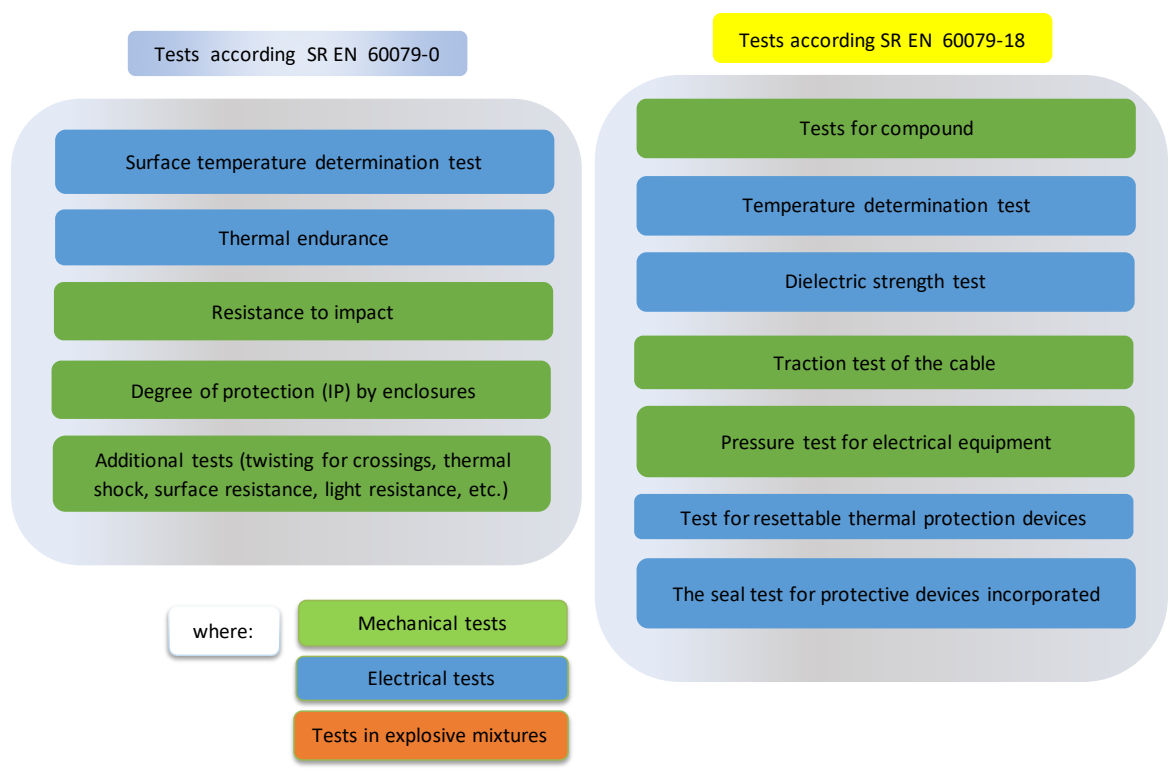

Fig. 3. Tests for equipment with protection type (general tests and encapsulation „m”). 


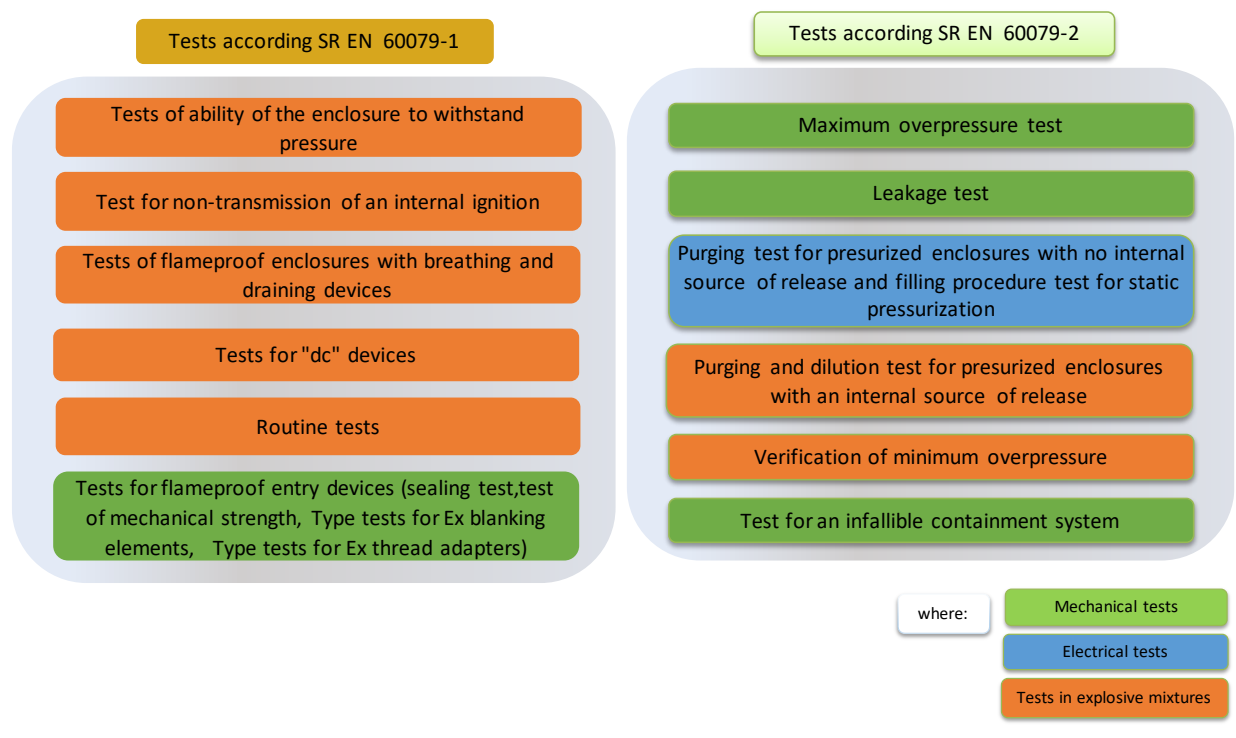

Fig. 4. Tests for equipment with protection type (flameproof enclosures „d” and pressurized enclosure ,p").
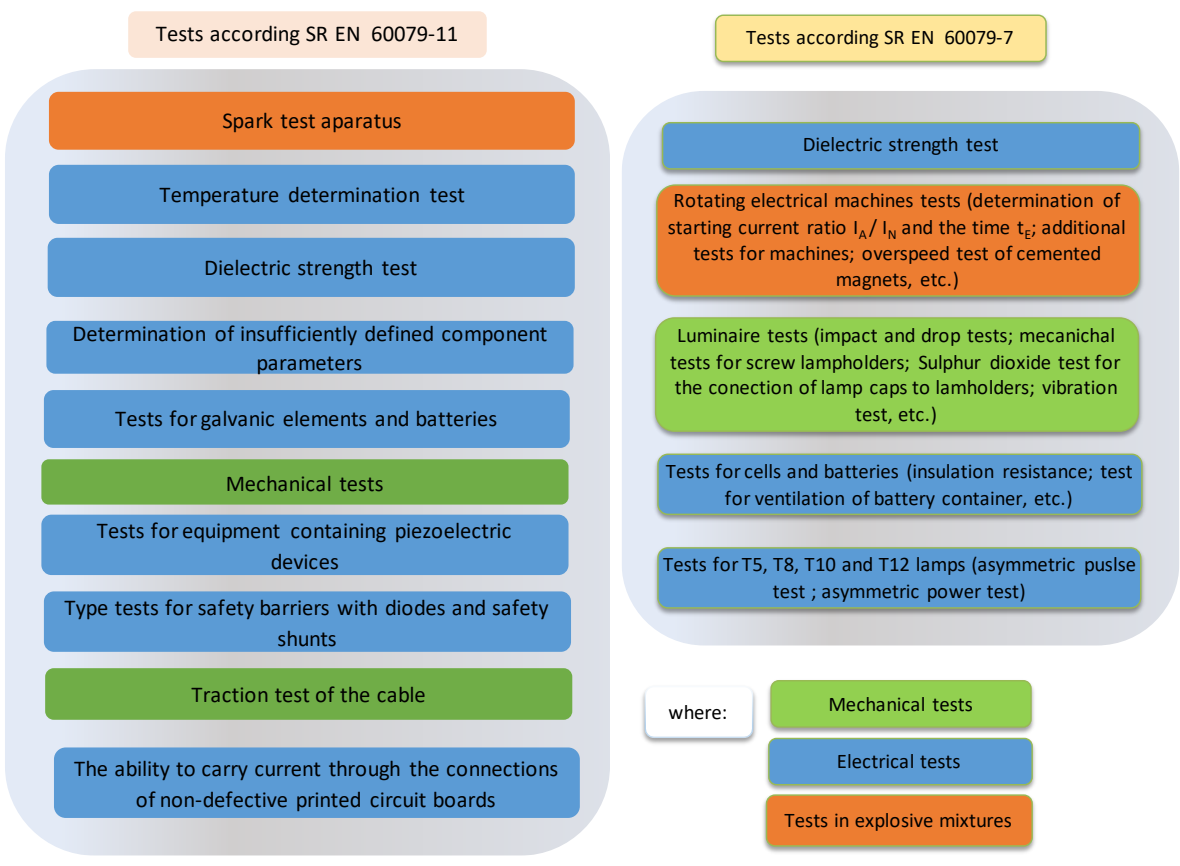

Fig. 5. Tests for equipment with protection type (intrinsic safety „,i” and increased safety „e”). 
After analysing, the tests imposed by relevant standards for the types of protection, it resulted the diagrams in Figure 6 and Figure 7, representing mechanical tests, electrical tests and tests in explosive mixtures.

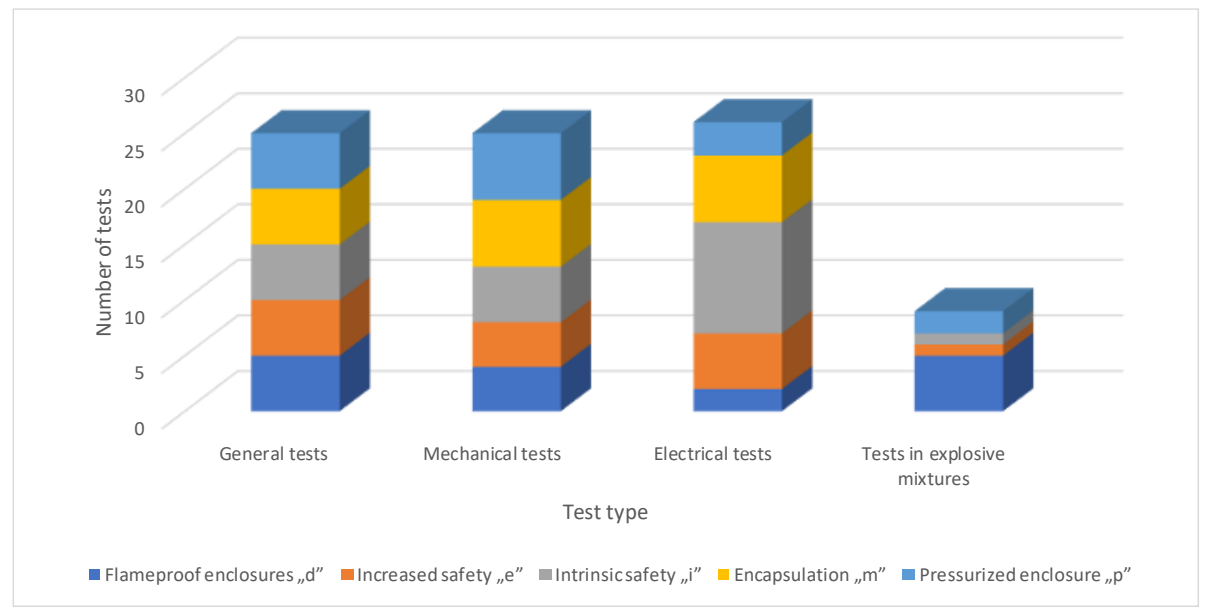

Fig. 6. Correlation between number of tests, type of tests and the type of protection.

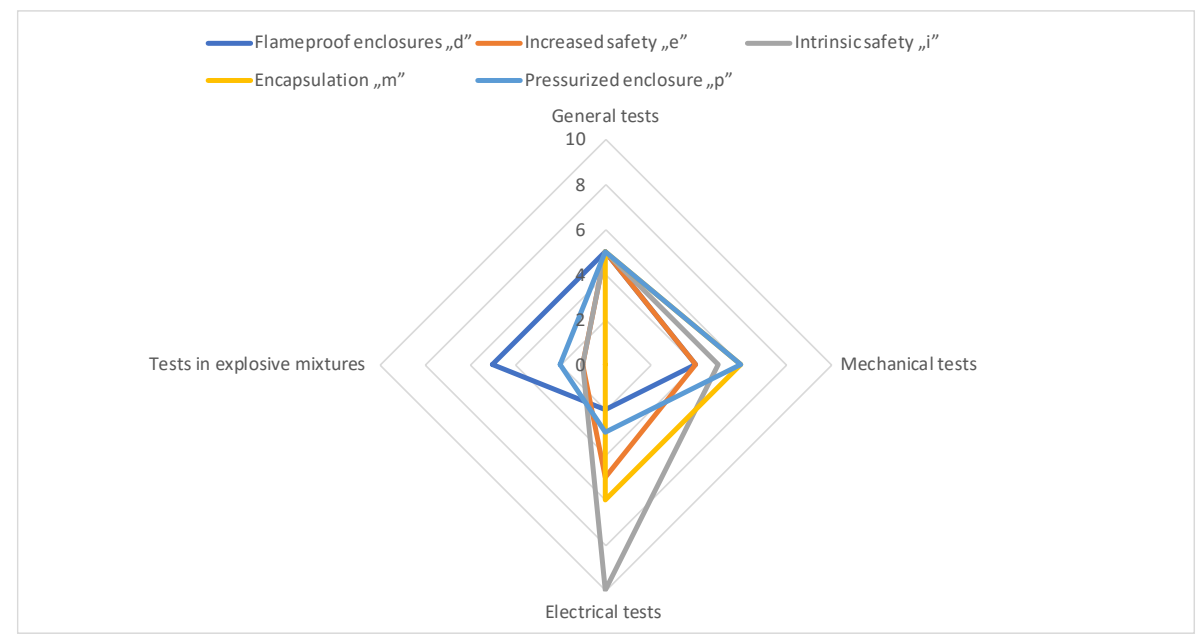

Fig.7. Representation of the number of tests, type of tests and the type of protection.

All types of protection require tests that are part of different technical fields. Tests for some types of protection do not require the use of explosive mixtures. Tests in accordance with the general requirements are symmetrical for all types of protection.

Electrical tests are predominant, then mechanical tests, general tests and tests in explosive mixtures. For the type of protection flameproof enclosure „d”, tests in explosive mixtures and mechanical tests are predominant, and for types of protection, intrinsic safety „i”, encapsulation „m” and increased safety „e", electrical tests are predominated. 


\section{Conclusions}

The risk of ignition of an explosive atmosphere may be reduced by the use of equipment, components and protective systems designed in accordance with the provisions of the explosion protection technical standards in force. The explosion risk assessment shall also take into account the determinations and interpretations of the flammable substance parameters. The main purpose of the explosion risk assessment is to increase the level of safety where an explosive atmosphere may occur.

Thus, the importance of determining, identifying the influencing factors and the measures to be taken to determine as accurately as possible the parameters of influence are necessary for explosion prevention and explosion protection, of major importance for occupational health and safety, to minimize losses (both human and material).

The paper presents relevant aspects for the evaluation of technical equipment for potentially explosive environments, useful aspects in the choice of materials, components of the equipment manufacturing process, all in order to minimize the risk of initiation atmospheres in which it is used. This equipment must correspond from a mechanical, electrical and constructive point of view, fact determined by the tests that must be performed depending on the type of protection. Moreover, based on the aspects specified in the paper, and after analysing each test required, in the future can be performed, using mathematical modelling, computer simulation that allows the evaluation of performance and parameters of technical equipment without considerable costs, minimum effort and maximum efficiency.

\section{References}

1. Directive 2014/34/EU of the European Parliament and of the Council of 26 February 2014 on the harmonisation of the laws of the Member States relating to equipment and protective systems intended for use in potentially explosive atmospheres (recast) (2014)

2. Standard SR EN 60079-10-1, Explosive atmospheres. Classification of areas. Explosive gas atmospheres (2015)

3. E. Ghicioi et al, EEMJ, 16, 1290-1294, (2017)

4. Standard SR EN IEC 60079-0, Explosive atmospheres - Part 0: Equipment - General requirements (2018)

5. Standard SR EN 60079-1, Explosive atmospheres - Part 1: Equipment protection by flameproof enclosures "d" (2015)

6. Standard SR EN 60079-2, Explosive atmospheres - Part 2: Equipment protection by pressurized enclosure "p" (2015)

7. Standard SR EN 60079-7, Explosive atmospheres - Part 7: Equipment protection by increased safety "e" (2016)

8. Standard SR EN 60079-11, Explosive atmospheres - Part 11: Equipment protection by intrinsic safety "i" (2012)

9. Standard SR EN 60079-18, Explosive atmospheres - Part 18: Equipment protection by encapsulation "m" (2015)

10. G. Pupazan et al, MATEC Web of Conferences 305, (2020)

11. C. Colda et al, IOP Conf. Ser.: Earth Environ. Sci. 609, (2020)

12. T. Csaszar et al, SGEM 2019, Critical point of pressurized enclosure found with CFD - an example, (Albena, Bulgaria, 2019) 